Scientific Journal of Faculty of Arts 10 (3) 2021, 123-138

\title{
A Pragmatic Study of Complaint Strategies as Used by Egyptian Arabic Speakers
}

\section{Sarah Maher Mustafa Mohamed Abdo}

Demonstrator - English Department - Faculty of Arts - Damietta University

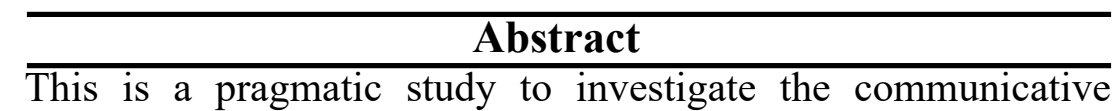
behavior of Egyptian Arabic Speakers (EASs) in the act of complaining. The participants of the study consist of 50 Egyptian Arabic Speakers (EASs). They are requested to complete a Discourse Completion Test (DCT) involving six complaintinducing scenarios. Trosborg's taxonomy of complaint strategies (1995) is used for classifying data, with three additional strategies presented in Yian's (2008) research. That is, the study yields eleven strategies for expressing complaints. The participants' performance is analyzed with respect to the social variables included in the complaint situation, namely, social distance and social power. Moreover, the severity of the wrong is, also, examined with the aim of identifying to which degree it influences the participants' selection of strategy. The findings of the study revealed that Egyptians use a variety of strategies when expressing complaints. Furthermore, participants' performance varies regarding the social distance and social power included in a specific context. In addition, the severity of the wrong plays a great role in affecting participants' way of complaining.

\section{Keywords:}

Speech Acts, Complaint Strategies, Social Power, Social Distance.

\section{Article history:}

Received 19 June 20121.

Received in revised form 2 July 2021.

Accepted 13 July 2021. 


\section{Introduction}

Language is the way speakers use for communication either inter-culturally, intra-culturally, or cross-culturally. In recent linguistic studies, there is a great interest in studying language usage in a wide range of societies with the aim of providing an authentic representation of the linguistic practices exercised in one each of them. This, by its turn, will add to the understanding of cross-cultural aspects of language and defining the points of similarity and dissimilarity amongst various societies.

Pragmatics is the domain that studies speakers' language in use. It focuses on the meaning of utterances in relation to the specific context in which it is uttered. A number of theories, such as presupposition, conversational implicature, and speech act, have been presented within pragmatics with the aim of exploring meaning of language as used by speakers. More specifically, speech act denotes the smallest component of speech used in communication. Speech act theory argues how words are used for doing things. Speech acts are believed to be applicable to all societies. Gass and Selinker argue that "[a]ll languages have a means of performing speech acts, and presumably speech acts themselves are universal, yet the form used in specific speech acts varies from culture to culture" (2008, p. 288). That is, speech acts are culturally specific, in the sense that, the ways in which they are conveyed differ across cultures.

Complaint is a speech act that could yield a breakdown in communication among speakers. It threatens the addressee's positive face as the complainer transfers a negative assessment of a wrongdoing, he holds the complainee responsible for. Also, it threatens the addressee's negative face as it implicitly or explicitly demands the complainee to compensate for his/her offence. Due to the face-threatening nature of complaining, it necessitates the use of communicative rituals in which mutual respect and support are guaranteed for each interactant in order to keep social relations. Accordingly, there is a need for studying the act of complaint in many languages and cultures in order to enrich 
the literature of complaining that is in need of an extensive investigation like other speech acts. This, by its turn, will help in providing the different linguistic and socio-cultural aspects of complaining in several speech communities.

\section{Review of literature}

\subsection{Speech acts}

Speech act theory was first introduced by the British philosopher J. Austin (1962) in his book How to do things with words. He argues that speech acts are "acts performed by utterances such as giving order, making promises, complaining, .... When we utter a sentence or a phrase, we are performing an act to which we expect our listeners to react with verbal or nonverbal behavior" (Jalilifar, 2009, p. 46). In Austin's view, utterances serve as actions. They can be produced, for example, to give promise, make request, offer apology, etc. He suggested that each speech act consists of three levels: locutionary, illocutionary, and perlocutionary. In 1969, Searle, one of Austin's students, presented a more refined and systematized elaboration of the theory of speech acts. Searle proposed five categories in which speech acts are classified into declaratives, representatives, directives, commissives, and expressives.

\subsection{Politeness}

Politeness is a universal term that applies to all societies and cultures, but it varies in how it is used and perceived, i.e., what is considered polite in a culture may not be considered polite in another. Politeness was put into a theory by a number of linguists such as Lakoff (1973), Brown and Levinson (1978), Fraser and Nolen (1981), and Leech (1983) to mention but a few. Brown and Levinson's (1987) model of politeness is said to be the most influential framework for investigating speech acts in pragmatic studies. Within the framework of politeness theory, complaint is classified as a face-threatening act for the hearer (Brown \& Levinson, 1987). It implies an explicit or implicit accusation to the hearer, thus, hurting his feelings and leaving him in an embarrassing condition. Brown and Levinson (1987) suggest three variables to affect a speaker's production of a certain 
speech act, namely, social distance, social power, and rank of imposition (or severity of the wrong as referred to in the complaint speech act).

\subsection{Speech act of complaint}

Complaint is an expressive speech act that conveys one's hidden negative feelings about a past or present action that the speaker recognizes as having an unfavorable impact on him (Olshtain \& Weinbach, 1993). In the act of complaining, the complainer conveys his dissatisfaction or aggravation toward an act that he or she considers as socially inappropriate. That is, a speaker is likely to complain when confronted with something that does not match his expectations and when irritated by an action for which he holds the complainee responsible.

Complaints are classified into two types: direct and indirect. A direct complaint denotes an expression of discontent and disapproval in a face-to-face confrontation in which the complainee is present at the time of the complaint (Murphy \& Neu, 1996). Therefore, a direct complaint is intrinsically a face-threatening act (FTA) that puts speakers' social relationships in jeopardy. It threatens the addressee's negative face since he does not feel free to act the way he wishes. Besides, it jeopardizes the addressee's positive face because of the complainer's negative evaluation of his behavior. In contrast to direct complaint which is voiced directly to the complainee, an indirect complaint is used by a complainer to vent his grievance to a third person in the absence of the person responsible for the offense. That is, an indirect complaint is frequently used to enhance social unity (Boxer, 2010).

Previous studies on the speech act of direct complaint investigated the communicative behavior of speakers in order to explore how different complaint strategies are employed with the aim of showing consideration to the addressee's face.

In 1987, Olshtain and Weinbach conducted a study with native and non-native Hebrew speakers to assess their pragmatic performance in the act of complaining. The responses of the participants were analyzed on the basis of: 
(1) the strategies used by each group and (2) the sociopragmatic factors that influenced their choices. The study came up with five strategies of complaining, namely, below the level of reproach, expression of annoyance or disapproval, explicit complaint, accusation and warning, and immediate threat. The findings revealed that participants in each group used all strategies. Moreover, when the addressee was of a lower status than the speaker, there was a greater propensity to employ more severe strategies and vice versa. The participants were different in the sense that unlike nonnative speakers (NNSs) who tend to mitigate their complaints, native speakers (NSs) were harsh in voicing their complaints.

Trosborg (1995) explored the production of complaints by native English speakers and Danish EFL (English as a foreign language) learners. The study developed a more refined categorization of complaint strategies. It developed four major categories and eight sub-categories of complaining. The four major categories divided into: (1) no explicit reproach, (2) expression of disapproval, (3) accusation, and (4) blame. Within these four categories, eight strategies are presented: hints, annoyance, ill consequences, indirect accusation, direct accusation, modified blame, explicit blame (behavior), and explicit blame (person). The results of the study indicated that NNSs express their dissatisfaction in a more indirect manner than NSs. Besides, they employed fewer complaints than the NSs. In addition, they had difficulty in expressing a "forceful" complaint. Furthermore, when faced with resistance from the complainee, NNSs showed less persistency in complaining.

Murphy and Neu (1996) conducted a cross-cultural study on the speech act of complaint between American English native speakers and Korean EFL learners regarding the components included in complaints and how Korean complaints are judged by NSs. Participants in both groups were asked to respond to a single scenario: 'complain to a professor about receiving a low grade.' The data confirmed that the complaint speech act consists of four primary components: an explanation of purpose, complaint, 
justification, and candidate solution: request. The findings demonstrated that the performance of Americans and Koreans was dissimilar, i.e., most Koreans employed criticism rather than complaint. Also, criticizers were deemed aggressive, disrespectful, and lacking in credibility by Americans.

Zhoumin (2011) examined complaint strategies as used by American and Chinese university students in relation to the social distance and social status described in the complaint situation. For data analysis, the study used a modified classification of complaint strategies based on the strategies proposed by Olshtain and Weinbach (1993) and Laforest (2002). This classification included seven strategies, namely, (1) ignoring and making no complaint, (2) allusion to the offensive act: below the level of reproach, (3) expression of annoyance or disapproval, (4) explicit complaint, (5) accusation and warning, (6) immediate threat, and (7) physical expression. The findings asserted that participants differed significantly in their choice of complaint strategies. Also, this study demonstrated the greater significance that the variable of social distance carried over the variable of social status.

Arafah and Kaharuddin (2019) examined the complaint strategies used by native English and Indonesian speakers. The data was collected using a Discourse Completion Test (DCT) in which participants were requested to submit their responses to three complaint situations. The study provided five main complaint strategies divided into two categories: (1) implicit strategy (IS) and (2) explicit strategy (ES). Strategies of reproach, annoyance, and silence are included in IS, whereas explicit complaint, accusation, and threat are presented in ES. The subjects of the study used similar complaint strategies in all three situations.

\section{Statement of the problem}

While there have been many studies on various kinds of speech acts, there has been very little research on complaints, despite the fact that it is one of the speech acts that requires a higher degree of appropriateness for its completion (Moon, 1996). complaint "has not been widely 
studied compared to other speech acts such as request or apology" (Ezzaoua, 2020, p. 7). For Egyptian Arabic Speakers (EASs), expressing complaint which is inherently face-threatening provides a fruitful ground for investigating as studying speech acts in Egyptian culture did not receive much attention, especially in the complaint speech act. Therefore, the present study examines EASs use of complaint strategies in terms of the type and frequency of strategies in different social contexts.

\section{Methodology}

\subsection{Research questions}

The purpose of this study is to find answers to the following questions:

1. How do Egyptian Arabic Speakers express complaints in Arabic?

2. Do social distance and social power between speakers induce a different usage of complaint strategies?

3. Does the severity of the wrong that a given context may transfer affect speakers' choice of strategies?

\subsection{Instruments}

Data for this study are collected using a written form of a Discourse Completion Test (DCT). The test consists of a series of situations in which participants are asked to respond in a realistic manner based on the context provided in each situation. To investigate complaint strategies in Arabic, 50 Egyptian speakers are selected randomly from undergraduate and postgraduate university students at various Egyptian universities. They were asked to fill in six written situations with what they would actually say if they encountered such stances, i.e., they respond to the questionnaire using their own dialect, which can be useful in demonstrating the distinctive aspects that differentiate the Egyptian Arabic dialect. The test was distributed to participants by posting it to the walls of a number of universities' official Facebook pages.

\subsection{Sample of the study}

This study includes 50 Egyptian Arabic Speakers enrolled in a number of Egyptian universities, including some undergraduate students as well as some graduate students 
pursuing either a master's or a Ph.D. degree. The ages of the subjects range from 17 to 35 years old. They were purposely chosen because they are the most appropriate category for being proficient in online communication (the method used for distributing the test and for collecting data).

\subsection{Research design and framework}

The test is designed to investigate Egyptian speakers' pragmatic performance in the act of complaining in relation to the social variables of social power and social distance provided in each DCT situation. That is, participants are asked to express complaints to superiors, equals/peers, and inferiors in order to determine their perception of the related social context. The test includes two situations with professors, two with colleagues and close friends, and two with strangers. Moreover, the test explores subjects' strategy selection in relation to the severity of the wrong implied.

\section{Data analysis}

This study employs a quantitative approach for analyzing data in which the responses of Egyptian subjects are calculated and tabulated in order to investigate the most frequently used strategies across the situations. The responses are analyzed and classified using a separate examination of each reply. Besides, percentages are counted in order to identify the frequency and distribution of strategies in each situation. This study adheres to Trosborg's (1995) categorization of complaint strategies, as well as three other categories adapted from Yian's (2008) study, namely, opting out, request for repair, and threat. Accordingly, the study yields a coding scheme consisting of eleven strategies of complaints which are arranged in descending order according to the degree of directness.

\section{Results and discussion}

The table below shows the frequency of each strategy, including the percentage submitted to each one of them. 
Table 1 Frequency of complaint strategies across the six situations

\begin{tabular}{|c|c|c|c|c|c|c|c|c|c|c|c|c|}
\hline \multirow{2}{*}{ Strategy } & \multicolumn{2}{|c|}{ S1 } & \multicolumn{2}{|c|}{ S2 } & \multicolumn{2}{|c|}{ S3 } & \multicolumn{2}{|c|}{ S4 } & \multicolumn{2}{|c|}{ S5 } & \multicolumn{2}{|c|}{ S6 } \\
\hline & $\mathbf{F}$ & $\%$ & $\mathbf{F}$ & $\%$ & $\mathbf{F}$ & $\%$ & $\mathbf{F}$ & $\%$ & $\mathbf{F}$ & $\%$ & $\mathbf{F}$ & $\%$ \\
\hline Opting out & 12 & $24 \%$ & 5 & $10 \%$ & 0 & $0 \%$ & 18 & $36 \%$ & 16 & $32 \%$ & 6 & $12 \%$ \\
\hline Hints & 0 & $0 \%$ & 0 & $0 \%$ & 0 & $0 \%$ & 0 & $0 \%$ & 1 & $2 \%$ & 0 & $0 \%$ \\
\hline Annoyance & 26 & $52 \%$ & 5 & $10 \%$ & 6 & $12 \%$ & 17 & $34 \%$ & 8 & $16 \%$ & 13 & $26 \%$ \\
\hline Ill consequences & 1 & $2 \%$ & 1 & $2 \%$ & 5 & $10 \%$ & 0 & $0 \%$ & 0 & $0 \%$ & 4 & $8 \%$ \\
\hline Indirect accusation & 8 & $16 \%$ & 11 & $22 \%$ & 11 & $22 \%$ & 5 & $10 \%$ & 10 & $20 \%$ & 0 & $0 \%$ \\
\hline Direct accusation & 2 & $4 \%$ & 0 & $0 \%$ & 9 & $18 \%$ & 0 & $0 \%$ & 0 & $0 \%$ & 0 & $0 \%$ \\
\hline Modified blame & 0 & $0 \%$ & 0 & $0 \%$ & 3 & $6 \%$ & 2 & $4 \%$ & 4 & $8 \%$ & 6 & $12 \%$ \\
\hline Explicit blame & 0 & $0 \%$ & 4 & $8 \%$ & 3 & $6 \%$ & 1 & $2 \%$ & 3 & $6 \%$ & 3 & $6 \%$ \\
\hline (behavior) & & & & & & & & & & & & \\
\hline Explicit blame & 0 & $0 \%$ & 5 & $10 \%$ & 5 & $10 \%$ & 0 & $0 \%$ & 7 & $14 \%$ & 2 & $4 \%$ \\
\hline (person) & & & & & & & & & & & & \\
\hline Request for repair & 1 & $2 \%$ & 13 & $26 \%$ & 2 & $4 \%$ & 7 & $14 \%$ & 1 & $2 \%$ & 9 & $18 \%$ \\
\hline Threat & 0 & $0 \%$ & 6 & $12 \%$ & 6 & $12 \%$ & 0 & $0 \%$ & 0 & $0 \%$ & 7 & $14 \%$ \\
\hline Total & 50 & $100 \%$ & 50 & $100 \%$ & 50 & $100 \%$ & 50 & $100 \%$ & 50 & $100 \%$ & 50 & $100 \%$ \\
\hline
\end{tabular}

Note: $S=$ Situation, $F=$ Frequency of strategy, $\%=$ percentage. 
In situation 1 , the complainer is confronted with a professor to complain about his low mark in a test. Professor is a person who has a social power over the complainer and a person with whom the social distance is very high. The statistical data provided for this situation reveal that more than half of the participants employ annoyance with a percentage of $52 \%$. That is, they opt for this strategy that yields less degree of directness in order to show some sort of respect to the complainee. Also, opting out is frequently used with a percentage of $24 \%$. It is the ultimate polite strategy employed in social interactions. Besides, indirect accusation is, also, utilized with a statistical rate of $16 \%$.

Situations 2 yields a low social distance between speakers. Accordingly, more direct strategies are expected to be frequent as the complainee in these contexts is a person who has no social power over the complainer. Therefore, request for repair is the most apparently used strategy with a percentage of $22 \%$. Furthermore, strategies of threat, explicit blame (person), annoyance, and opting out are employed with no significant difference in their occurrences.

Besides, the speakers included in situation 3 are socially equal. That is, no need for formality or indirect styles of speech is required. Participants express their complaints using various types of strategies depending on their perception of the wrongdoing involved in the context. The high frequently used strategy in this situation is indirect accusation with a percentage of $22 \%$. Direct accusation comes second with $18 \%$. In addition, strategies of annoyance and threat as well as strategies of ill consequences and explicit blame (person) record the same statistical value with $12 \%$ and $10 \%$ respectively.

In situation 4, the addressed person is, also, a professor. In this situation, participants, also, show a propensity to opt for strategies of annoyance and opting out more than other strategies. However, whereas annoyance is the most favored strategy in situation 1, there is no significant difference in employing opting out and annoyance which record percentages of $36 \%$ and $34 \%$ respectively. Moreover, 
participants employ request for repair with 14\% which imply a high degree of directness and is often recurrent in situations where the social distance between speakers is low. This is ascribed to the fact that different degrees of favoritism to certain strategies depend on the related social context and the severity of the wrong that a situation may transfer. That is, participants' assessment of the severity of the wrong conveyed in situation 4 is higher than in situation 1.

In situation 5, the speaker complains about his colleague for telling him a wrong timing of a lecture. The participants show, somehow, a dissimilar usage of strategies other than those applied in situation 3 though the addressed person is the same person. Opting out is the most favored strategy involving $32 \%$ of the total responses. Indirect accusation comes second with 20\%. Also, they employ annoyance and explicit blame (person) with percentages of $16 \%$ and $14 \%$.

In situation 6 , the social variables of social power and social distance included in the context are similar to those implied in situation 2. However, the participants' selection of strategies in this situation is far different from their selection in situation 2. In this situation, the speaker complains about an observer's behavior inside the exam headquarters. The data show that the strategy of annoyance represents $26 \%$ of the total responses, followed by request for repair and threat with percentages of $18 \%$ and $14 \%$. In addition, participants log the same statistical values in using modified blame and opting out with a percentage of $12 \%$. It is emphasized, again, that speakers' communicative behavior is determined by the situational variation (severity of the wrong) included in the situation.

\section{Conclusion}

This pragmatic study seeks to examine the complaint strategies employed by Egyptian Arabic speakers. It, also, investigates how the subjects' choice of strategy is influenced by social factors, namely, social power and social distance. Moreover, the severity of the wrong is tested in relation to the participants' way of complaining. The findings showed that 
Egyptians employ a variety of strategies in order to express complaints. In addition, social variables are found to have a great impact on the participants' selection of strategies. That is, in situations 1 and 4 where high social distance and social power are conveyed, participants employ strategies of opting out and annoyance more frequently than other strategies as a means of showing consideration to the addressee's face. In situations 2 and 6 , participants show a propensity to adopt more direct strategies along with direct ones when complaining about a speaker who has no social power over the complainee. Therefore, strategies of request for repair, threat, annoyance, and opting out are the most recurrent among participants. Besides, participants use strategies of indirect accusation, annoyance, and explicit blame (person) in situations 3 and 5 more repeatedly than other strategies when they complain to peers. Finally, it is observed that the severity of the wrong serves to be a dominant factor that affects participants' production of complaints. An example is the participants' dissimilar performance in situations 1 and 4 when expressing complaints to a professor. In situation 4, participants use more direct complaints than in situation 1, i.e., the strategy of request for repair is used. This signifies that their perception of the wrong in situation 4 is higher than that implied in situation 1. Generally, the findings of the study confirm that the linguistic production of speakers is influenced by the various social contexts in relation.

\section{References}

Arafah, B., \& Kaharuddin, A. (2019). The representation of complaints in English and Indonesian discourses. Opción, 35, 501-517.

Austin, J. L. (1962). How to do things with words. Oxford University Press.

Boxer, D. (2010). Complaints: How to gripe and establish rapport. In A. Martinez-Flor \& E. Uso-Juan (Eds.), Speech act performance: Theoretical, empirical and methodological issues (pp. 163-178). John Benjamins. https://doi.org/10.1075/11lt.26.10box 
Brown, P., \& Levinson, S. (1987). Politeness: Some universals in language usage. Cambridge University Press.

Ezzaoua, O. (2020). The interlanguage of Moroccan EFL learners: The case of complaints. Studies in Literature and Language, 20(1), 6-11. http://dx.doi.org/10.3968/11483

Gass, S., \& Selinker, L. (2008). Second language acquisition: An introductory course (3rd ed.). Routledge.

Jalilifar, A. (2009). Request strategies: Cross-sectional study of Iranian EFL learners and Australian native speakers. English Language Teaching, 2(1), 46-61.

Laforest, M. (2002). Scenes of family life: Complaining in everyday conversation. Journal of pragmatics, 34(10-11), 1595-1620.

Moon, Y. (1996). Interlanguage features of Korean EFL learners in the communicative act of complaining [Doctoral dissertation]. Indiana University.

-Murphy, B. \& Neu, J. (1996). My grade's too low: The speech act set of complaining. In S. Gass \& J. Neu (Eds.), Speech acts across cultures: Challenges to communication in a second language (pp. 191-216). Mouton de Gruyter.

Olshtain, E., \& Weinbach, L. (1987). Complaints: A study of speech act behavior among native and nonnative speakers of Hebrew. In J. Verschueren \& M. Bertuccelli-Papi (Eds.), The pragmatic perspective: Selected papers from the 1985 international pragmatics conference (pp. 195-208). John

Benjamins.

https://doi.org/10.1075/pbcs.5.15ols

Olshtain, E., \& Weinbach, L. (1993). Interlanguage features of the speech act of complaining. In G. Kasper \& S. Blum-Kulka (Eds.), Interlanguage Pragmatics (pp. 108-122). Oxford University Press.

Trosborg, A. (1995). Interlanguage pragmatics: Requests, complaints, and apologies. Mouton de Gruyter. https://doi.org/10.1515/9783110885286 
Yian, W. (2008). A study of the speech act of complaining: Cross-cultural perspectives and interlanguage perspectives. Intercultural Forum, 1(2). http://comm.louisville.edu/iic/IF\%20Journal/IF\%201 $\% 20(2) \% 202008 /$ ifl( 2)2008-wang-yian.html

Zhoumin, Y. (2011). A contrastive study of American and Chinese university students' complaining strategies. Chinese Journal of Applied Linguistics, 34(1),

111-125.

https://doi.org/10.1515/CJAL.2011.008 


\section{Appendix 1}

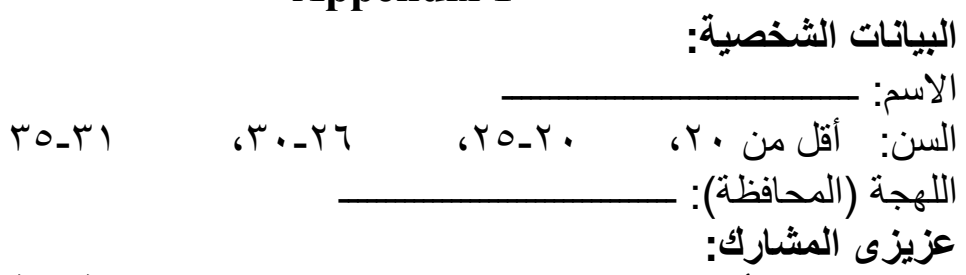

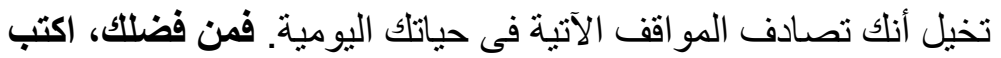

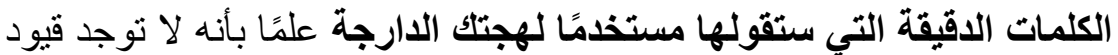

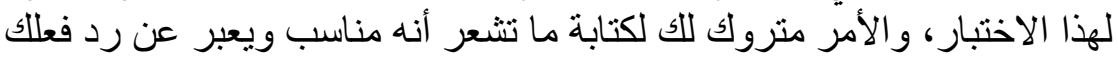

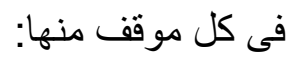
الموقف الأول: أستاذلك الجامعى في مقرر من المقررات المهرة والتي التي اعتقدت

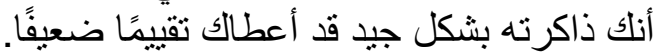
ردك:

الموقف الثاني: ذهبت إلى كافتيريا الكلية للحصول على شئ نشربه، ولكن بعد مغادرة المكان وجدته منتهي الصلاحية.

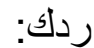

الموقف الثالث: استعار زميل لك دفتر محاضراتك؛ لإكمال بعض الأجزاء الناقصة لديه، ثم تتفاجأ بأن هناك بعض الصفال الصفحات المفقودة بعد إرجاعه هذا الدفتر إليك.

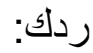

الموقف الرابع: أحد أساتذتك الجامعيين زاد في آخر محاضرة فصلين كاملين

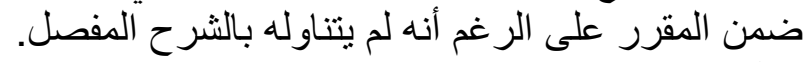

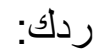

الموقف الخامس: أبلغك أحد زملائك بأن موعد المحاضرة سيكون في تمام

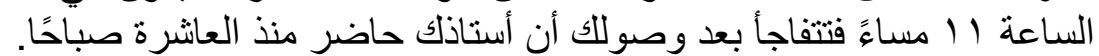

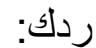

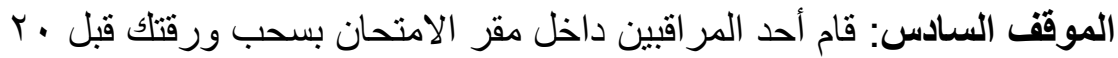
دقيقة من المو عد المحدد رغم علمه أنك لم الم تتته من الامتحان بعد.

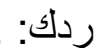




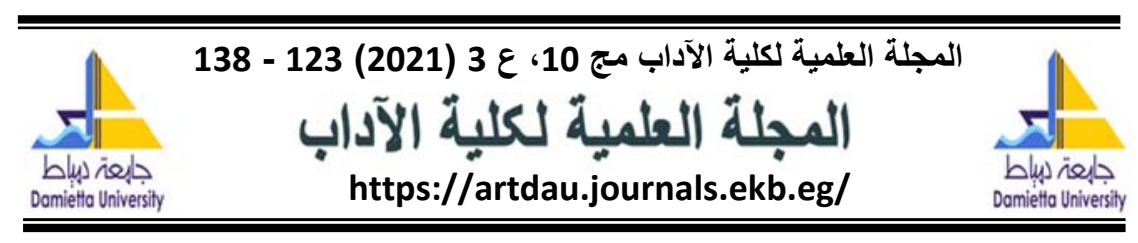

دراسة عملية لأساليب الثكوى المستخدمة لاي المصريين الناطقين باللغة العربية العينة

سارة ماهر مصطفي محمد عبدة

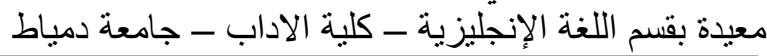

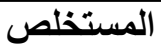

تعد هذه الدراسة دراسة عملية للبحث في السلوك التواصلي للمصريين الناطقين

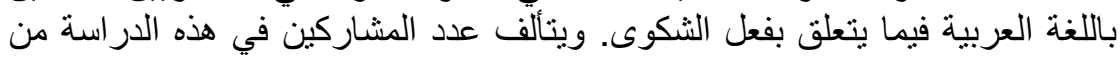

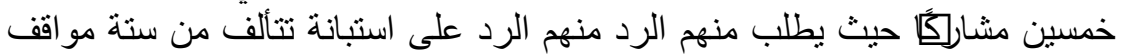

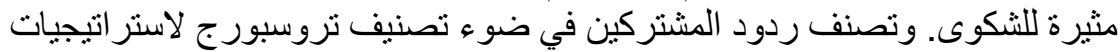

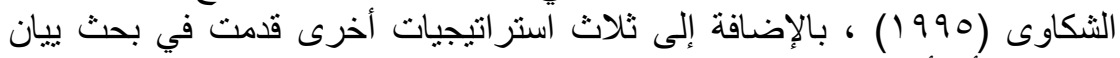

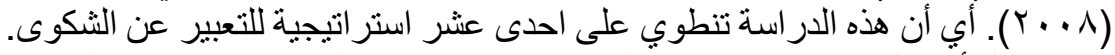

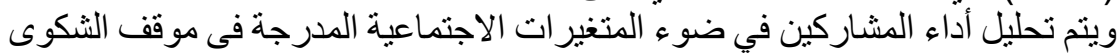

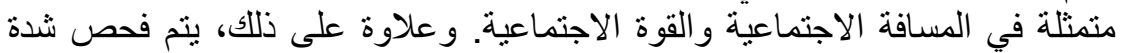

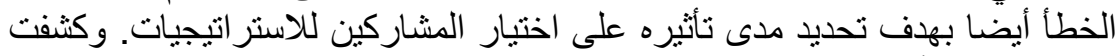

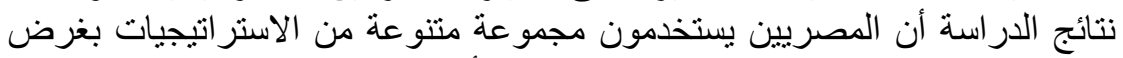

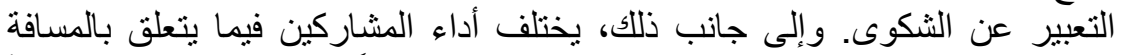

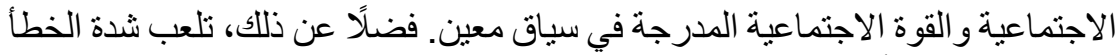

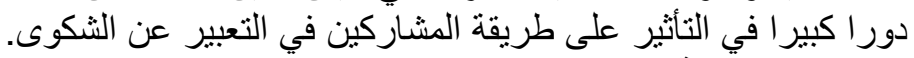
الكلمات المفتاحية: التئية

أفعال الكلام، استراتيجيات الثكوى، القوة الاجتماعية، المسافة

$$
\text { الاجتماعية. }
$$

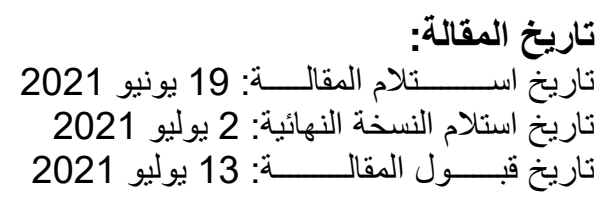

